\title{
Sometimes evolution requires a revolution
}

\author{
Joseph S. Coselli, MD
}

\footnotetext{
From the Division of Cardiothoracic Surgery, Michael E. DeBakey Department of Surgery, Baylor College of Medicine; Section of Adult Cardiac Surgery, Department of Cardiovascular Surgery, Texas Heart Institute; and CHI St Luke's Health-Baylor St Luke's Medical Center, Houston, Tex.

Disclosures: Author has nothing to disclose with regard to commercial support.

Received for publication Aug 22, 2017; accepted for publication Aug 26, 2017; available ahead of print Sept 22 , 2017.

Address for reprints: Joseph S. Coselli, MD, One Baylor Plaza, BCM 390, Houston, TX 77030 (E-mail: jcoselli@ bcm.edu).

J Thorac Cardiovasc Surg 2017;154:e99-100

$0022-5223 / \$ 36.00$

Copyright (C) 2017 by The American Association for Thoracic Surgery

http://dx.doi.org/10.1016/j.jtcvs.2017.08.087
}

Dietl and colleagues ${ }^{1}$ report on the long-term follow-up of a rather remarkable case that they first carried out in 2001. The procedure involved a 44-year-old male patient with Marfan syndrome, who, having months earlier survived emergent replacement of the ascending aorta following extensive acute aortic dissection, underwent hybrid open debranching and endovascular aortic arch reconstruction to repair a 6.5$\mathrm{cm}$ aneurysm of the distal aortic arch. The proximal landing zone was a previously replaced portion of the ascending aorta, and the distal landing zone relied on native aortic tissue. This case, reported by Dietl and colleagues in 2003, described the earliest use of off-pump hybrid reconstruction of an aortic arch.

Over time, the patient required additional open and endovascular aortic repairs. Twelve months after the original procedure, further endovascular repair was necessary to correct an endoleak at the distal landing zone. Nearly 7 years after the original procedure, a hybrid endovascular approach was used to repair a Crawford extent III thoracoabdominal aortic aneurysm. Lastly, in 2014, nearly 13 years after hybrid arch repair and after the patient was admitted for headaches, severe stenosis of the left common carotid artery graft and retrograde flow of the left vertebral artery was identified; the latter was suspected to be the etiology of an endoleak responsible for an enlarging 9-cm aneurysm at an unspecified location. This was corrected with a right common carotid to left common carotid artery bypass, ligation of the left vertebral artery, and a left common carotid artery to subclavian artery bypass. The authors state that the headaches resolved but do not mention the resolution of the $9-\mathrm{cm}$ aneurysm. Ultimately, the patient died during December 2016, 15 years after the original off-pump hybrid reconstruction of the transverse aortic arch, due to metastatic angiosarcoma.

Open procedures for aortic arch pathology are technically challenging and carry a consequential rate of morbidity and mortality. Following the success of abdominal and thoracic endovascular aortic repair, encroachment of endovascular techniques into the rate of $11.9 \%$.

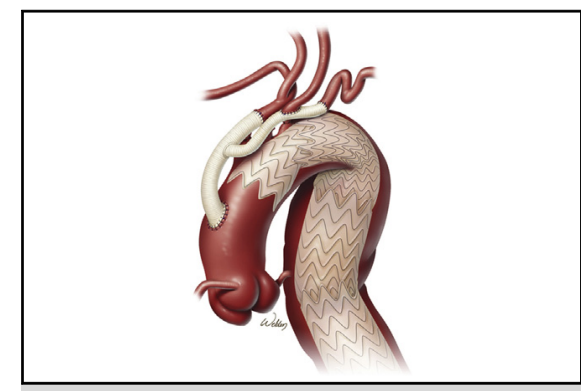

Hybrid aortic arch repair: Debranching and stentgrafting in a patient without genetic thoracic aortic disease.

Central Message

Endovascular aortic repair in patients with genetic thoracic aortic disease is seldom definitive-long-term surveillance may reveal the need for additional repair.

See Article page e95.

transverse aortic arch was a natural progression. For the most part, this has been accomplished with off-label uses of available off-the-shelf devices in the form of what has been described as hybrid techniques-those that combine open and endovascular aortic repair. ${ }^{3-6}$ In a meta-analysis of hybrid aortic arch repair, Moulakakis and colleagues reported an overall stroke rate of $7.6 \%$ and a mortality

In their complex case report, Dietl and colleagues ${ }^{1}$ state that "conventional surgical resection using cardiopulmonary bypass and deep hypothermic circulatory arrest versus off-pump aortic arch reconstruction and endovascular stent grafting were offered as alternative approaches. The patient preferred the second option because of fear of neurological complications." However, at that time, the neurologic complications of hybrid arch procedures were entirely unknown, and thus, an accurate comparison of the potential risks between the 2 approaches would have simply been impossible. Even with data accumulated and clinical experience since the group's first off-pump management of an aortic arch aneurysm, ${ }^{2}$ the clear distinction between the risks of conventional open repair and the hybrid arch repair case described herein remains difficult to determine, especially because additional late complications were noted in this case. In two propensity score-matched comparisons, both Hiraoka and colleagues ${ }^{6}$ and Tokkuda and colleagues ${ }^{4}$ found that postoperative outcomes were similar between hybrid arch 
repairs and open arch repairs; however, the rate of stroke was higher in the hybrid arch repairs group.

In this complex case report, ${ }^{1}$ although it is clearly possible that further distal aortic repair would have been needed to treat the expansion of extensive residual aortic dissection, even if the original arch repair had been performed in an open fashion, it is also possible that the hybrid arch repair accelerated aortic dilatation because the distal landing zone was in doubly compromised aortic tissue-residual chronic dissection superimposed on genetically compromised tissue. The risk of elective open arch repair, even that requiring a redo median sternotomy, may not be as great as feared.

Until we know whether hybrid surgery results in worse, equivalent, or better outcomes than open surgery, we need to be forthcoming to our patients, ourselves, and our colleagues. Additionally, questions remain regarding the evolution of hybrid endovascular therapies-it is quite possible that hybrid therapies are simply an interim transitional technique between open and purely endovascular aortic arch replacement. ${ }^{7}$ Only time will tell whether revolution is needed to protect patients from the temptations of emerging technology.

\section{References}

1. Dietl CA, Langsfeld M, Sanchez AM, Samedi VG. Hybrid reconstruction of the aortic arch. A 15-year follow-up. J Thorac Cardiovasc Surg. 2017;154:e95-7.

2. Dietl CA, Kasirajan K, Pett SB, Wernly JA. Off-pump management of aortic arch aneurysm by using an endovascular thoracic stent graft. J Thorac Cardiovasc Surg. 2003;126:1181-3.

3. Moulakakis KG, Mylonas SN, Markatis F, Kotsis T, Kakisis J, Liapis CD. A systematic review and meta-analysis of hybrid aortic arch replacement. Ann Cardiothorac Surg. 2013;2:247-60.

4. Tokuda Y, Oshima H, Narita Y, Abe T, Araki Y, Mutsuga M, et al. Hybrid versus open repair of aortic arch aneurysms: comparison of postoperative and mid-term outcomes with a propensity score-matching analysis. Eur J Cardiothorac Surg. 2016;49:149-56.

5. Sun LZ, Ma WG, Zhu JM, Zheng J, Liu YM, Ziganshin BA, et al. Sun's procedure for chronic type A aortic dissection: total arch replacement using a tetrafurcate graft with stented elephant trunk implantation. Ann Cardiothorac Surg. 2013;2:621-8.

6. Hiraoka A, Chikazawa G, Totsugawa T, Tamura K, Ishida A, Sakaguchi T, et al. Objective analysis of midterm outcomes of conventional and hybrid aortic arch repair by propensity-score matching. J Thorac Cardiovasc Surg. 2017;154:100-6.e1.

7. Yang J, Liu Y, Duan W, Yi D, Yu S, Ma R, et al. A feasibility study of total endovascular aortic arch replacement: from stent-graft design to preclinical testing. J Thorac Cardiovasc Surg. 2016;151:1203-12. 